\title{
Decision Support System of Global Brands in Fashion Marketing Strategy for Entrepreneurship
}

\author{
Elsayed Ahmed Elnashar* \\ Faculty of Specific Education, Kafrelsheikh University, Egypt
}

*Corresponding author: Elsayed Ahmed Elnashar, Full-Professor of textiles \& Apparel, Faculty of Specific Education, Kafrelsheikh University, El-Geish Street, 33516 Kaferelsheikh City, Egypt

submission: 漹July 19, 2018; Published: 迤 July 24, 2018

\section{Opinion}

Sustainability strategy of global brands in fashion marketing strategy is a key factor that most organizations in today's society strive to achieve. The concept of strategy sustainability is about meeting the needs of the present without compromising the ability of future generations to meet their own. For a long time, global brands in fashion marketing strategy impact had been the main focus for many organizations craving a sustainability strategy philosophy. It is also becoming more and more popular in public works. Today, sustainability strategy of decision support system is essential for consideration when constructing power generator system along with the selection of suitable fashion of biofuels, Solar Energy of textiles (SOLTEX), fashion public buildings, fashion roads of geotextiles and fashion freight transportation system, green supplier selection, sustainable fashion marketing electricity generation technologies and manufacturing decision support system among other types of projects.

In a world of limited resources that are diminishing by the minute, it is important for project planners and developers to think evaluate and select such technologies that will reduce the impact of the project on the fashion marketing, minimize energy demand, and exploit fashion of renewable energy sources. Hence, the practice of green activities has become mandatory to balance these conflicts; even manufacturing processes cannot make an exception. Green issues have gained more importance in contemporary globalization. Real-world problems often require the consideration of a large number of mutually conflicting criteria that affect the final decision. So, decision makers need a systematic mathematical approach to conduct those analyses.

The growing complexity in modern social-economics or engineering environments or systems has forced the researchers to solve a complicated problem by using multi-criteria decision support system (DSSGBF) approaches. However, traditional (DSSGBF) research mainly focuses on reaching the highest economic value or efficiency; issues related to sustainability strategy are still not much explored. This proposed edited volume makes a humble effort to discuss and address the challenges in implementation of decisionsupport system models in the context of green and sustainable engineering, criteria identification, quantification, comparison, selection, and analysis in the context of manufacturing, supply fashion chain, fashion of textiles \& apparel, fashion transportation and fashion energy sectors. thus, this article aims to collect highquality research's which will apply different (DSSGBF) methods and their extensions for assessing sustainability strategy in a wide range of real time engineering case studies and applications that address valuable issues and provide an in depth knowledge.

Global brands in fashion marketing strategy engineering needs an effervescent revolution which highly depends upon fashion energy of industry, Strategy for entrepreneurship and economy. Sustainability strategy aims to conserve fashion energy and natural resources, and to ensure that they have minimal impact on the environment and society. In the twenty-first century the sustainability strategy of fashion energy and fashion transportation systems is on the top of the political agenda in many countries around the world and governments are establishing policies towards a sustainable, low emissions fashion energy future. Sustainability strategy modeling issues for entrepreneurship strategy diverse ranges of engineering applications have received an extensive grows in the last twenty years.

Discussions about the implementation of green fashion strategies may lead to affordable product price, faster time-tomarket, higher quality, and advantages relative to enterprise competition. It targets at fulfilling the needs of the present without compromising the ability of future generations to meet their own needs. Investigators in area of engineering fashion and fashion design seek to demonstrate advanced tools and models rather than relying on classical and trial and error methods in order to enhance quality of engineering process and productivity.

The main aim of this article is to enrich the vision of scholars, researchers and professionals who are working in the area of manufacturing, materials, supply chain, Design, social communication website, logistics, energy, optimization and industrial engineering and to create further awareness about the need for improvement in their respective fields. 
In the proposed editorial article, different types of decisionsupport systems models and their extensions have been proposed in order to provide a strong framework. Hybrid or integrated models, data mining tools, fuzzy or interval or rough extensions and other aggregated forms are few among them. Thus, fashion marketing strategy for entrepreneurship aims to products highquality papers which apply different decision support methods for sustainability strategy assessment in a wide range of fashion design and engineering applications that address valuable inputs and key issues in implementing green concepts. As the following figure show elements relationship of decision support system of global brands in fashion marketing strategy for entrepreneurship (Figure 1).

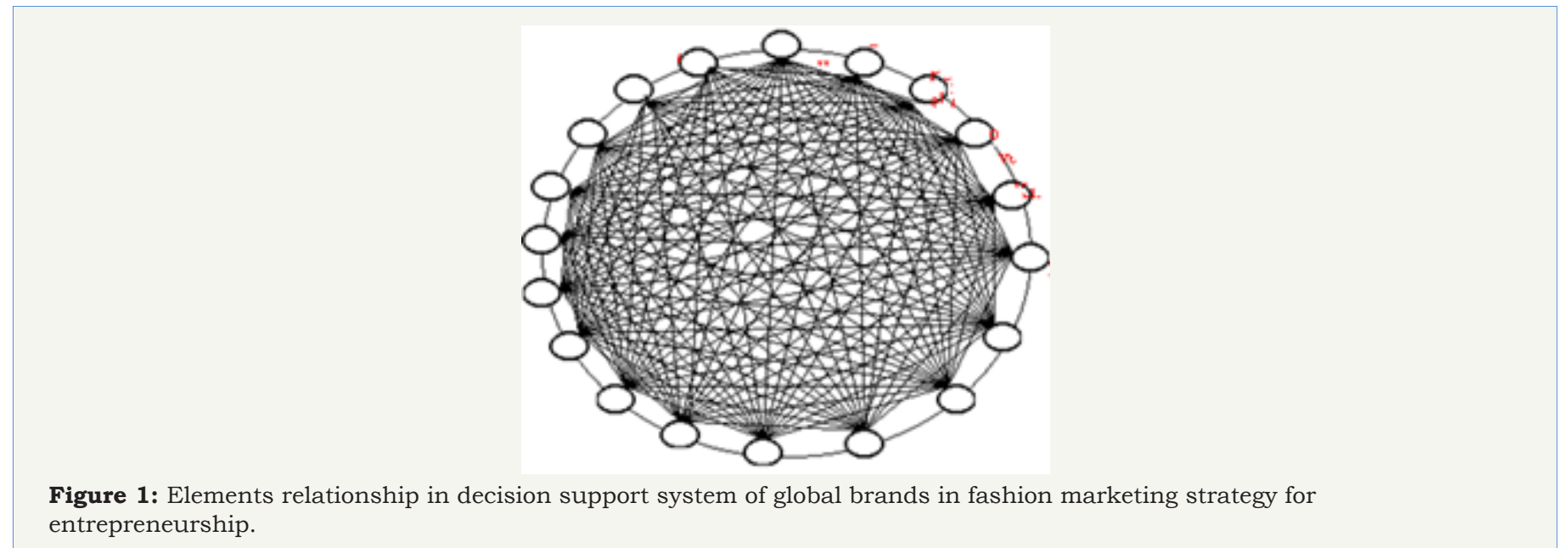

Entrepreneurship fashion marketing communities in area of management, economics, business sciences, mechanical and manufacturing technologies are able to use, apply and implement models for the researchers who work in manufacturing, industrial engineering, design, operations, supply chain and logistics, energy and management sectors.
Creative Commons Attribution 4.0 International License

For possible submissions Click Here

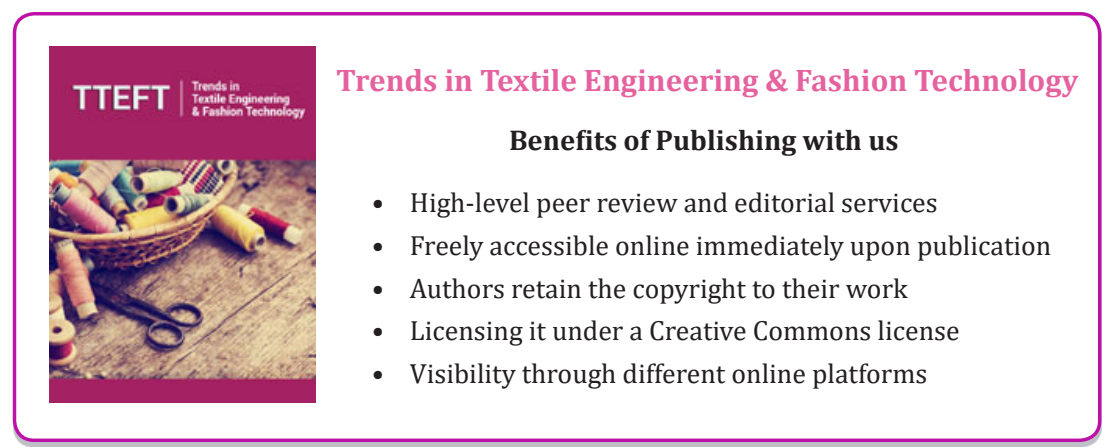

